\title{
Comparative Fates of Intravenously and Orally Administered Aldosterone: Evidence for Extrahepatic Formation of Acid-hydrolyzable Conjugate in Man *
}

\author{
Turner Bledsoe, Grant W. Liddle, † Anne Riondel, Donald P. Island, \\ Dennis Bloomfield, and Bruce Sinclair-Smith \\ (From the Department of Medicine, Vanderbilt University School of Medicine, Nashville, Tenn.)
}

It is well established that the liver is a major site of metabolic inactivation of aldosterone. In 1962 Coppage, Island, Cooner, and Liddle (2) reported that the human liver was capable of converting aldosterone both to its acid-hydrolyzable conjugate $(\mathrm{AHC})^{1}$ and to tetrahydroaldosterone. The same study also demonstrated that aldosterone was almost completely inactivated during a single passage through the normal liver. More recent studies by Luetscher and associates (4) have indicated that the normal liver extracts about $97 \%$ of the aldosterone delivered to it by the arterial circulation, and the studies of Bougas and co-workers $(5,6)$ have indicated that in subjects with minimal cardiac dysfunction the rate of splanchnic clearance of aldosterone amounts to about $89 \%$ of the hepatic blood flow.

The fact that the liver metabolizes almost all of the aldosterone presented to it does not imply that the liver is the only site of metabolism of aldosterone. Sandor and Lanthier ( 7 ) observed that kidney slices could convert aldosterone to AHC. From their analyses of hepatic and peripheral venous plasma after the continuous infusion of tritiated aldosterone into human subjects, Bougas and co-workers $(5,6)$ calculated the extrasplanchnic clearance rate of aldosterone to be approximately

\footnotetext{
* Submitted for publication July 26, 1965; accepted November 10, 1965.

These studies were supported in part by the following grants-in-aid from the National Institutes of Health of the U. S. Public Health Service: 5-K6-AM-3782, 8-MO1FR-95, T1-AM-5092, and 5-RO1-AM-05318. Reported in part at the January 1965 Meeting of the Southern Society for Clinical Investigation (1).

† Address requests for reprints to Dr. Grant W. Liddle, Dept. of Medicine, Vanderbilt University School of Medicine, Nashville, Tenn. 37203.

1 Recent studies by Underwood and Tait (3) have indicated that AHC is probably aldosterone glucosiduronate, conjugated at position 18 of the aldosterone molecule.
}

$17 \%$ of the total metabolic clearance rate. Luetscher and associates (4) infused tritiated aldosterone into human subjects and measured this steroid and its principal metabolic derivatives in arterial plasma, in hepatic and renal venous plasma, and in urine. From their observation that AHC appeared in the urine at a greater rate than could be expected from the renal extraction of this metabolite from the plasma flowing through the kidney, these authors inferred that the kidney converted aldosterone to $\mathrm{AHC}$.

In comparing the metabolic fate of orally administered aldosterone with that of the intravenously administered hormone, we found that a smaller proportion of it was ultimately excreted as $\mathrm{AHC}$ when the oral route was employed. The same observation had been made earlier (2), but its significance was not recognized. Of particular importance was the fact that the route of administration appeared only to affect the degree of formation of AHC without appreciably altering the total excretion of aldosterone metabolites or the degree of formation of the most abundant metabolite, tetrahydroaldosterone. In normal subjects orally administered aldosterone is well absorbed but is almost completely metabolized in one passage through the liver (2). Therefore, to explain the fact that intravenously administered aldosterone is more abundantly converted to AHC than is orally administered aldosterone, we postulated that there might be a quantitatively important extrahepatic site at which aldosterone is selectively converted to AHC. In testing this idea, it was necessary to have a means of distinguishing the metabolites of aldosterone given intravenously from those of aldosterone given simultaneously by the oral route. Therefore, aldosterone given by one route was isotopically labeled and that given by the other route was not. The relative contribu- 
tions of orally or intravenously administered hormone to a urinary metabolite could then be determined by comparing the specific radioactivity of the administered combination with that of the urinary metabolite.

The present communication has three purposes: to quantify the proportion of AHC formed outside of the liver, to add further evidence that the kidney is capable of converting aldosterone to AHC, and to explore the implications of these observations relative to clinical studies of aldosterone metabolism.

\section{Methods}

Clinical methods. The comparative fates of orally administered and intravenously administered aldosterone were studied in four patients without endogenous aldosterone. Three had idiopathic Addison's disease, and one had undergone bilateral adrenalectomy as treatment for Cushing's disease. Thus, in this group of patients, the input of aldosterone was known in absolute terms. Each patient received the following combinations of aldosterone at various times in his study: intravenous aldosterone$1,2-{ }^{8} \mathrm{H}$ (SA $20 \mathrm{c}$ per mmole) plus intravenous unlabeled aldosterone; oral aldosterone-1,2- ${ }^{8} \mathrm{H}$ plus intravenous unlabeled aldosterone; oral aldosterone-1,2- ${ }^{-3} \mathrm{H}$ plus oral unlabeled aldosterone; and intravenous aldosterone-1,2- ${ }^{8} \mathrm{H}$ plus oral unlabeled aldosterone. The doses of aldosterone-1,2- ${ }^{8} \mathrm{H}$ ranged from 2 to $8 \mu \mathrm{c}$; the doses of unlabeled aldosterone ranged from 100 to $200 \mu \mathrm{g}$ in various studies. Urine was collected for 48 hours after the administration of aldosterone for determination of the specific activities of the aldosterone metabolites.

The renal metabolism of aldosterone was studied during cardiac catheterization of one patient who had mitral valve disease but not congestive heart failure, and who had normal hepatic and renal function. Aldosterone-4-4 $\mathrm{C}$ (SA $46 \mathrm{mc}$ per mmole) was administered in a priming dose of $2.2 \times 10^{5} \mathrm{cpm},{ }^{2}$ and after a 15-minute interval a sustaining infusion of aldosterone- $4{ }^{14} \mathrm{C}$ was begun at a rate of $4.5 \times 10^{3} \mathrm{cpm}$ per minute. The bladder was drained by an indwelling catheter and washed at the beginning and end of the collection period with physiologic saline. The urine was collected over a 19-minute period that began 30 minutes after the priming injection of aldosterone-4- ${ }^{14} \mathrm{C}$. During this collection period simultaneous blood samples were obtained from the femoral artery and renal vein for analysis of aldosterone$4-{ }^{14} \mathrm{C}$, aldosterone-AHC-4-14 $\mathrm{C}$, and urea.

Laboratory methods. The specific activity of the acidhydrolyzable conjugate of aldosterone was determined by a modification (8) of the double isotope dilution derivative technique of Kliman and Peterson (9).

Tetrahydroaldosterone was also determined by the double isotope derivative technique. A one-fifth portion

\footnotetext{
${ }^{2}$ The counting efficiency for ${ }^{3} \mathrm{H}$ was $24 \%$ and for ${ }^{14} \mathrm{C}$, $44 \%$.
}

TABLE I

Chromatographic systems

\begin{aligned} \hline \hline System & \multicolumn{1}{c}{ Composition by volume } \\ \hline I & Benzene:methanol:water $4: 2: 1 \\$ II & Isooctane: $t$-butanol:water $10: 5: 9 \\$ III & $n$-Heptane:methanol:water $4: 3: 1 \\$ IV & Cyclohexane:nitromethane:methanol $6: 1: 1 \\$ V & Cyclohexane:benzene:methanol:water $4: 2: 4: 1 \\$ VI & $n$-Hexane: $t$-butanol:methanol:water $500: 225: 225: 220\end{aligned}$

of the 48-hour urine specimen was adjusted to $\mathrm{pH} 5.2$ and incubated at $37^{\circ} \mathrm{C}$ with $\beta$-glucuronidase (Ketodase) for 48 hours and then extracted with ethyl acetate (equal volume $\times 3$ ). The organic phase was washed successively with $0.1 \mathrm{~N} \mathrm{NaOH}$, water, and $0.1 \%$ acetic acid and evaporated under vacuum. This extract was further purified by partition between benzene and water (equal volumes $\times 10$ ) and subsequent extraction of the combined aqueous phases into dichloromethane. This fraction was then chromatographed in system I for 8 hours $\left(R_{\text {cort } 1 \text { sol }}=\right.$ 0.76). See Table I for paper chromatographic systems. The radioactive peak corresponding to tetrahydroaldosterone was eluted in ethanol, dried, and then acetylated (9) with acetic anhydride-1- ${ }^{14} \mathrm{C}$ (SA $2 \mathrm{mc}$ per mmole). The tetrahydroaldosterone-3, 18, 21-triacetate so formed was purified by chromatography in system III for 7 hours $\left(R_{\text {deoxycort teosterone acetate }}=1.05\right)$ and in system IV for 36 hours $\left(R_{\text {deoxycort costerone acetate }}=0.70\right.$ ). Partial hydrolysis of the purified triacetate was carried out by using $0.4 \% \mathrm{KHCO}_{3}$ in methanol at $24^{\circ} \mathrm{C}$ for 8 hours under nitrogen. The reaction was terminated by the addition of water and extraction into dichloromethane: The resulting monoacetate was purified to constant specific activity by successive chromatography in system V for 8 hours $\left(R_{\text {adrenosterone }}=0.67\right)$ and in system VI for 7 hours ( $R_{\text {deoxycort teosterone acetate }}=0.72$ ). The ${ }^{14} \mathrm{C}$ and ${ }^{3} \mathrm{H}$ of the final eluate were counted in a Tricarb scintillation spectrometer (10). Total excretion of urinary radioactivity was measured by the technique of Luetscher and associates (11).

In the quantitative study of renal metabolism of aldosterone-4- ${ }^{14} \mathrm{C}$, knowledge of the recovery of aldosterone released from AHC during acid hydrolysis as well as that of free aldosterone was considered to be of critical importance. Because the yield of aldosterone from the conjugate by acid hydrolysis may be unpredictably variable (3), known quantities of purified AHC- $7_{\alpha}^{-}{ }^{-} \mathrm{H}^{3}$ were added to the samples of blood or urine before hydrolysis and purification, and in the final calculations it was assumed that the recovery of $\mathrm{AHC}-4-{ }^{14} \mathrm{C}$ was the same as that observed for AHC-7. ${ }^{8} \mathrm{H}$. The recovery of free aldosterone-4- ${ }^{14} \mathrm{C}$ was calculated in analogous fashion, adding known quantities of aldosterone-1,2- ${ }^{3} \mathrm{H}$ to the plasma and urine. Of the total urine collected, a one-third aliquot was used to measure the excretion of the free aldosterone-4- ${ }^{14} \mathrm{C}$, and one-tenth was used to measure the excretion of AHC-4- ${ }^{14} \mathrm{C}$. Twenty $\mathrm{ml}$ of plasma diluted

${ }^{3}$ Kindly made available by Dr. Richard H. Underwood. 
TABLE II

Specific activity of urinary tetrahydroaldosterone or urinary acid-hydrolyzable conjugate as a function of the route of administration of labeled aldosterone*

\begin{tabular}{|c|c|c|c|c|c|c|}
\hline Subject & $\begin{array}{l}\text { Route of } \\
\text { labeled } \\
\text { aldo }\end{array}$ & $\begin{array}{c}\text { Specific } \\
\text { activity } \\
\text { administered } \\
\text { combination }\end{array}$ & $\begin{array}{l}\text { Specific } \\
\text { activity } \\
\text { thaldo }\end{array}$ & $\begin{array}{l}\text { SA thaldo } \div- \\
\text { SA administered } \\
\text { combination }\end{array}$ & $\begin{array}{l}\text { Specific } \\
\text { Activity } \\
\text { AHC }\end{array}$ & $\begin{array}{c}\text { SA AHC } \div \\
\text { SA administered } \\
\text { combination }\end{array}$ \\
\hline & & $c p m / n g$ & $c p m / n g$ & & $c p m / n g$ & \\
\hline E.M. & $\begin{array}{l}\text { iv } \\
\text { Oral }\end{array}$ & $\begin{array}{l}55 \\
55\end{array}$ & $\begin{array}{l}64 \\
65\end{array}$ & $\begin{array}{l}1.16 \\
1.18\end{array}$ & $\begin{array}{l}52 \\
30\end{array}$ & $\begin{array}{l}0.94 \\
0.54\end{array}$ \\
\hline E.V. & $\begin{array}{l}\text { iv } \\
\text { Oral }\end{array}$ & $\begin{array}{l}22 \\
22\end{array}$ & $\begin{array}{l}27 \\
18\end{array}$ & $\begin{array}{l}1.22 \\
0.82\end{array}$ & $\begin{array}{l}26 \\
13\end{array}$ & $\begin{array}{l}1.18 \\
0.59\end{array}$ \\
\hline R.B. & $\begin{array}{l}\text { iv } \\
\text { Oral }\end{array}$ & $\begin{array}{l}7.7 \\
3.8\end{array}$ & $\begin{array}{l}7.8 \\
3.8\end{array}$ & $\begin{array}{l}1.01 \\
1.00\end{array}$ & $\begin{array}{l}9.0 \\
2.6\end{array}$ & $\begin{array}{l}1.16 \\
0.68\end{array}$ \\
\hline W.H. & $\begin{array}{l}\text { iv } \\
\text { Oral }\end{array}$ & $\begin{array}{l}34 \\
34\end{array}$ & 31 & 0.91 & $\begin{array}{l}35 \\
20\end{array}$ & $\begin{array}{l}1.02 \\
0.58\end{array}$ \\
\hline
\end{tabular}

* Abbreviations : aldo = aldosterone, thaldo = tetrahydroaldosterone, and AHC = acid-hydrolyzable conjugate. $\dagger$ All four subjects were lacking endogenous aldosterone and received unlabeled aldosterone, 100 to $200 \mu \mathrm{g}$, intravenously.

with 2 vol of saline was used for analysis of both free aldosterone-4- ${ }^{14} \mathrm{C}$ and $\mathrm{AHC}-4-{ }^{14} \mathrm{C}$. Each sample was extracted twice with $6 \mathrm{vol}$ of dichloromethane, and the organic phase was reserved for analysis of free aldosterone. The aqueous phase, containing $\mathrm{AHC}$, was then taken to $\mathrm{pH} 1$ with $60 \% \mathrm{HCl}$ by using a Beckman $\mathrm{pH}$ meter and allowed to stand at $30^{\circ} \mathrm{C}$ for 24 hours. The aldosterone thus released by acid hydrolysis was then extracted twice into 6 vol of dichloromethane. Each organic phase was then washed successively with $\frac{1}{10}$ vol $0.1 \mathrm{~N} \mathrm{NaOH}$, distilled water, and $0.1 \%$ acetic acid and dried in vacuo. The dried extracts were taken up in $25 \%$ ethanol and extracted first with 2 vol of cyclohexane (the organic phase was discarded) and then with $10 \mathrm{vol}$ of dichloromethane. The dichloromethane extracts were dried and then chromatographed in system 1 for 6 hours (aldosterone $R_{\mathbf{f}}=$ 0.38). The radioactive peak corresponding to aldosterone was eluted and counted in a liquid scintillation counter.

Renal blood flow was estimated by two methods: 1) plasma and urinary urea were determined and renal blood flow was calculated with the Fick principle; 2) analysis of the dye dilution curves using indocyanine green in- jected during the collection period allowed calculation of the renal blood flow by the method of Shillig (12).

\section{Results}

Fate of aldosterone after oral vs. intravenous administration. Absorption of aldosterone from the gastrointestinal tract was judged to be virtually complete, since the amount of ${ }^{3} \mathrm{H}$ appearing in the urine after oral administration of aldosterone-1,2${ }^{3} \mathrm{H}$ was approximately the same as the amount appearing after intravenous administration of the labeled steroid. In three subjects the recoveries of urinary ${ }^{3} \mathrm{H}$ within 48 hours after the intravenous administration of labeled aldosterone were 92,76 , and $76 \%$; recoveries after oral administration were 98,84 , and $65 \%$, respectively.

When labeled aldosterone was given with unlabeled aldosterone by the oral route, the specific

TABLE III

Specific activity of urinary tetrahydroaldosterone or urinary acid-hydrolyzable conjugate as a function of the route of administration of labeled aldosterone

\begin{tabular}{|c|c|c|c|c|c|c|}
\hline Subject* & $\begin{array}{l}\text { Route of } \\
\text { labeled } \\
\text { aldo }\end{array}$ & $\begin{array}{c}\text { Specific } \\
\text { activity } \\
\text { administered } \\
\text { combination }\end{array}$ & $\begin{array}{l}\text { Specific } \\
\text { activity } \\
\text { thaldo }\end{array}$ & $\begin{array}{l}\text { SA thaldo } \div \\
\text { SA administered } \\
\text { combination }\end{array}$ & $\begin{array}{l}\text { Specific } \\
\text { activity } \\
\text { AHC }\end{array}$ & $\begin{array}{c}\text { SA AHC } \div \\
\begin{array}{c}\text { SA administered } \\
\text { combination }\end{array}\end{array}$ \\
\hline & & $c p m / n g$ & $c p m / n g$ & & $c p m / n g$ & \\
\hline E.M. & $\begin{array}{l}\text { Oral } \\
\text { iv }\end{array}$ & $\begin{array}{l}51 \\
51\end{array}$ & $\begin{array}{l}44 \\
46\end{array}$ & $\begin{array}{l}0.86 \\
0.90\end{array}$ & $\begin{array}{l}43 \\
76\end{array}$ & $\begin{array}{l}0.84 \\
1.49\end{array}$ \\
\hline E.V. & $\begin{array}{l}\text { Oral } \\
\text { iv }\end{array}$ & $\begin{array}{l}22 \\
22\end{array}$ & $\begin{array}{l}23 \\
20\end{array}$ & $\begin{array}{l}1.04 \\
0.90\end{array}$ & $\begin{array}{l}23 \\
34\end{array}$ & $\begin{array}{l}1.04 \\
1.54\end{array}$ \\
\hline R.B. & $\begin{array}{l}\text { Oral } \\
\text { iv }\end{array}$ & $\begin{array}{l}7.7 \\
7.7\end{array}$ & $\begin{array}{l}7.9 \\
8.1\end{array}$ & $\begin{array}{l}1.02 \\
1.05\end{array}$ & $\begin{array}{r}8.8 \\
15.5\end{array}$ & $\begin{array}{l}1.14 \\
2.01\end{array}$ \\
\hline
\end{tabular}

* All subjects were lacking endogenous aldosterone and received unlabeled aldosterone, 100 to $200 \mu \mathrm{g}$, orally. 
TABLE IV

Study of renal metabolism of aldosterone-4-14C

\begin{tabular}{|c|c|c|c|}
\hline Determination & Recovery & Measurement* & Result \\
\hline $\begin{array}{l}\text { Renal plasma flow (urea extraction, Fick) } \\
\text { Renal plasma flow (indocyanine green) } \\
\text { Mean renal plasma flow (RPF) }\end{array}$ & $\%$ & $\begin{array}{l}358 \mathrm{ml} \text { per minute } \\
451 \mathrm{ml} \text { per minute } \\
404 \mathrm{ml} \text { per minute }\end{array}$ & $p m / m i n u t e$ \\
\hline $\begin{array}{l}\text { Free aldosterone entering kidneys } \\
\text { Free aldosterone leaving in renal vein } \\
\text { Free aldosterone leaving in urine } \\
\text { Renal extraction of free aldosterone }\end{array}$ & $\begin{array}{l}13 \\
29 \\
24\end{array}$ & $\begin{array}{l}\text { Arterial plasma }=4.9 \mathrm{cpm} \text { per } \mathrm{ml} \times \mathrm{RPF}= \\
\text { Renal vein plasma }=2.4 \mathrm{cpm} \text { per } \mathrm{ml} \times \mathrm{RPF}= \\
\text { Aldosterone entering minus aldosterone leaving }=\end{array}$ & $\begin{array}{r}1,984 \\
977 \\
10 \\
=\quad 997\end{array}$ \\
\hline $\begin{array}{l}\text { AHC entering kidneys } \\
\text { AHC leaving in renal vein } \\
\text { AHC leaving in urine } \\
\text { Renal production of AHC }\end{array}$ & $\begin{array}{l}64 \\
18 \\
15\end{array}$ & $\begin{array}{l}\text { Arterial plasma }=0.7 \mathrm{cpm} \text { per } \mathrm{ml} \times \mathrm{RPF}= \\
\text { Renal vein plasma }=0.9 \mathrm{cpm} \text { per } \mathrm{ml} \times \mathrm{RPF}= \\
\text { AHC leaving minus } \mathrm{AHC} \text { entering }=\end{array}$ & $\begin{array}{l}286 \\
376 \\
206 \\
296\end{array}$ \\
\hline
\end{tabular}

* All measurements are corrected for recovery of aldosterone- $1,2-{ }^{3} \mathrm{H}$ or $\mathrm{AHC}-7-{ }^{3} \mathrm{H}$.

activities of the urinary metabolites (tetrahydroaldosterone and AHC) approximated the specific activity of the administered steroid. Similarly, when labeled and unlabeled aldosterone were both administered intravenously, the specific activity of each of the urinary metabolites approximated the specific activity of the administered steroid. There was no reason to believe, therefore, that labeling of the steroid modified its metabolism.

Whenever labeled aldosterone was administered by one route and unlabeled aldosterone by the other route, however, the specific activity of the urinary $\mathrm{AHC}$ was quite different from the specific activity of the total administered aldosterone (oral plus intravenous). Thus, after oral administration of labeled aldosterone, along with intravenous administration of unlabeled aldosterone, the specific activity of the urinary $\mathrm{AHC}$ was from 32 to $46 \%$ lower than that of the administered combination (Table II). Conversely, after intravenous administration of labeled aldosterone along with oral administration of unlabeled aldosterone, the specific activity of the urinary AHC was from 49 to $101 \%$ higher than that of the administered combination (Table III). These observations are consistent with the view that as much as one-half of the AHC is formed at some extrahepatic site.

The route of administration of aldosterone had comparatively little effect on the specific activity of the tetrahydroaldosterone appearing in the urine. Whether the labeled steroid was given intravenously and the unlabeled steroid orally or vice versa, the specific activity of the tetrahydroaldosterone was found to be approximately that of the administered combination (Tables II and III). This observation is consistent with the view that tetrahydroaldosterone is formed principally in the liver.

Renal metabolism of aldosterone. The rates at which free aldosterone and AHC entered the kidney via the arterial circulation and left the kidney via the renal vein and through urinary excretion were determined during the constant infusion of aldosterone- $4-{ }^{14} \mathrm{C}$ to a patient with normal hepatic and renal function (Table IV). It was found that approximately twice as much free aldosterone entered the kidney via the arterial circulation as left the kidney via the venous circulation and urine combined. At the same time approximately twice as much AHC left the kidney via venous circulation plus urine as entered via the arterial circulation. This observation indicates that the kidney is capable of converting aldosterone to AHC.

\section{Discussion}

Interpretation of studies of the fate of aldosterone after oral vs. intravenous administration. Of fundamental importance in the interpretation of the present study is the fact that, in normal subjects, orally administered aldosterone is well absorbed but is almost completely metabolized in one passage through the liver. When labeled aldosterone was given orally and unlabeled aldosterone intravenously, the specific activity of the urinary AHC was about one-half that of the administered combination, implying that the intravenously administered steroid had access to some extrahepatic site of AHC formation, whereas the 
orally administered aldosterone was metabolized only by the liver. This view was confirmed by the fact that, when labeled aldosterone was given intravenously and unlabeled aldosterone orally, the specific activity of urinary AHC was about twice that of the administered combination. If, as suggested by Underwood and Tait (3), about $20 \%$ of secreted aldosterone is converted to $\mathrm{AHC}$, it would appear from our data that about $10 \%$ is so converted in the liver and $10 \%$ in extrahepatic tissues.

In contrast to $\mathrm{AHC}$, tetrahydroaldosterone appears to be formed principally in the liver, inasmuch as the specific activity of this excretory product was not significantly different from that of the administered combination of labeled plus unlabeled aldosterone regardless of the routes of administration.

Interpretation of studies of renal metabolism of aldosterone. The idea that there is an extrahepatic site of formation of AHC has been substantiated by the observation that the quantity of AHC leaving the kidney via the renal vein plus that excreted into the urine exceeds the quantity of AHC reaching the kidneys via the arterial circulation. Furthermore, more free aldosterone disappears as it traverses the renal circulation than can be accounted for by the excretion of free aldosterone in the urine. These observations confirm those published recently by Luetscher and co-workers (4). It seems probable that the disappearance of aldosterone and appearance of AHC are merely two aspects of the same process, the conversion of aldosterone to AHC by renal tissue.

Implications for aldosterone metabolism in hepatic insufficiency. The concept that extrahepatic tissues are capable of forming AHC but are relatively or absolutely incapable of forming tetrahydroaldosterone provides an explanation for certain observations in patients with liver disease. In hepatic insufficiency, the ratio of urinary $\mathrm{AHC}$ to tetrahydroaldosterone may be increased as much as threefold over the normal ratio $(2,13)$. In this disease, hepatic clearance of aldosterone is slowed; as a consequence, a greater proportion of secreted (or injected) aldosterone is available for extrahepatic conversion to AHC.

Implications for studies of "renal clearance" of $A H C$. It was initially reported by Siegenthaler, Peterson, and Frimpter that the renal clearance of
AHC exceeds that of inulin (14). This conclusion was based upon determinations of the quantity of AHC excreted per unit time and the concentration of $\mathrm{AHC}$ in blood; the renal arteriovenous difference in AHC was not measured. Thus, the possibility that more AHC might be leaving the kidney than was being delivered to the kidney by the arterial circulation could not have been appreciated. If some of the AHC that is produced de novo in the kidney is excreted into the urine without re-entering the general circulation, then the apparent renal clearance would be spuriously elevated, as pointed out in a more recent publication by Gfeller and Siegenthaler (15). The true renal clearance of $\mathrm{AHC}$ can be calculated only if preformed AHC can somehow be distinguished from that formed by the kidney. This could be accomplished by utilizing an infusion of isotopic AHC or, if the subject has no endogenous aldosterone, an infusion of unlabeled AHC.

Implications for determination of aldosterone secretion rates. From inspection of the basic formula for the calculation of aldosterone secretion rates (dose of labeled aldosterone in counts per minute divided by the specific activity of metabolite in counts per minute per microgram), it is apparent that erroneously high results would be obtained if the labeled aldosterone were to be administered orally and if AHC were used as the metabolite. Endogenous aldosterone has access to the extrahepatic as well as to the hepatic site of AHC formation. In contrast, orally administered tracer would have access only to the hepatic site. Thus, proportionately more of the AHC would be formed from the endogenous precursor than from the orally administered labeled precursor. Therefore, the specific activity of the metabolite would be low and the apparent secretion rate correspondingly high. In the present study, aldosterone secretion was simulated by the intravenous infusion of unlabeled aldosterone to four patients without functioning adrenals. When labeled aldosterone was given orally, the calculated "secretion rate" exceeded actual input by 47 to $85 \%$. It is apparent, therefore, that determinations of aldosterone secretory rate in which AHC serves as the unique metabolite of aldosterone will be valid only if the labeled aldosterone is administered parenterally. 


\section{Summary}

Although the liver is the major site of metabolic inactivation of aldosterone, two lines of evidence have been developed indicating that considerable conversion of aldosterone to its acid-hydrolyzable conjugate (AHC) occurs in extrahepatic tissues. First, when aldosterone is administered orally, the proportion that is converted to AHC is considerably less than when it is administered intravenously. This sort of discrepancy is not observed in the formation of tetrahydroaldosterone, the other major metabolite of aldosterone. Second, direct measurements of aldosterone and AHC in arterial blood, renal venous blood, and urine, during constant infusion of labeled aldosterone, have indicated that aldosterone is converted to $\mathrm{AHC}$ in the kidney. In the absence of liver disease, up to $50 \%$ of the total formation of AHC may take place in extrahepatic tissues.

The fact that significant quantities of AHC are formed by the kidney has explanatory value with respect to 1 ) the high proportion of aldosterone that is excreted as AHC in patients with liver disease, 2) the high apparent "renal clearance" of AHC that has been reported previously, and 3) the spuriously high estimates of aldosterone secretion rate that can be obtained by the isotope dilution method if isotopic aldosterone is administered by the oral route.

\section{References}

1. Bledsoe, T., A. M. Riondel, D. P. Island, and G. W. Liddle. Evidence for extrahepatic metabolism of aldosterone. Clin. Res. 1965, 13, 70.

2. Coppage, W. S., Jr., D. P. Island, A. E. Cooner, and G. W. Liddle. The metabolism of aldosterone in normal subjects and in patients with hepatic cirrhosis. J. clin. Invest. 1962, 41, 1672.

3. Underwood, R. H., and J. F. Tait. Purification, partial characterization and metabolism of an acid labile conjugate of aldosterone. J. clin. Endocr. 1964, 24, 1110.
4. Luetscher, J. A., E. W. Hancock, C. A. Camargo, A. J. Dowdy, and G. W. Nokes. Conjugation of 1, 2- ${ }^{3} \mathrm{H}$-aldosterone in human liver and kidneys and renal extraction of aldosterone and labeled conjugates from blood plasma. J. clin. Endocr. 1965, 25, 628.

5. Bougas, J., C. Flood, B. Little, J. F. Tait, and R. Underwood. Dynamic aspects of aldosterone metabolism in Aldosterone, E. E. Baulieu and P. Robel, Eds. Philadelphia, F. A. Davis, 1964, pp. 25-50.

6. Tait, J. F., J. Bougas, B. Little, S. A. S. Tait, and C. Flood. Splanchnic extraction and clearance of aldosterone in subjects with minimal and marked cardiac dysfunction. J. clin. Endocr. 1965, 25, 219.

7. Sandor, T., and A. Lanthier. The metabolism of aldosterone. II. Studies "in vitro" and "in vivo" in man. Acta endocr. (Kbh.) 1962, 39, 87.

8. Bledsoe, T., D. P. Island, A. M. Riondel, and G. W. Liddle. Modification of aldosterone secretion and electrolyte excretion in man by a chemical inhibitor of 18-oxidation. J. clin. Endocr. 1964, 24, 740.

9. Kliman, B., and R. E. Peterson. Double isotope derivative assay of aldosterone in biological extracts. J. biol. Chem. 1960, 235, 1639.

10. Okita, G. T., J. J. Kabara, F. Richardson, and G. V. LeRoy. Assaying compounds containing $\mathrm{H}^{3}$ and $\mathrm{C}^{14}$. Nucleonics 1957, 15 (no. 6), 111.

11. Luetscher, J. A., A. P. Cohn, C. A. Camargo, A. J. Dowdy, and A. M. Callaghan. Aldosterone secretion and metabolism in hyperthyroidism and myxedema. J. clin. Endocr. 1963, 23, 873.

12. Schillig, S. Indicator-dilution techniques in the estimation of renal blood flow. Amer. Heart J. 1964, 68, 675.

13. Hurter, R., and J. D. N. Nabarro. Aldosterone metabolism in liver disease. Acta endocr. (Kbh.) 1960, 33, 168.

14. Siegenthaler, W. E., R. E. Peterson, and G. W. Frimpter. The renal clearance of aldosterone and its major metabolites in Aldosterone, E. E. Baulieu and P. Robel, Eds. Philadelphia, F. A. Davis, 1964, pp. 51-72.

15. Gfeller, J., and W. Siegenthaler. Die renale Clearance des Aldosterons und seiner Hauptmetabolite beim Menschen. Acta endocr. (Kbh.) 1965, 49, 510. 